\title{
THE INCIDENCE OF CONGENITAL PYLORIC STENOSIS
}

\author{
BY \\ GEORGE DAVISON \\ (From the Babies' Hospital, Royal Victoria Infirmary and Newcastle General Hospital, \\ Newcastle-on-Tyne)
}

The present investigation was undertaken in order to determine, with as much precision as possible, the incidence of manifest congenital pyloric stenosis in the United Kingdom. The conclusion reached is that this incidence is in the order of three per thousand live births.

The term 'manifest' requires some explanation. There is evidence, given by Wallgren (1937), Malmberg (1939), Bexelier (1939) and Lewis (1944), that the anatomical deformity of pyloric stenosis may be present without symptoms. Clinical experience suggests that such an occurrence is rare, but no estimate of frequency can at present be made. Further, there are cases of pyloric stenosis in which the symptoms are so mild that the diagnosis is not made, and which undergo spontaneous cure without treatment. The frequency of such cases, again, can not be assessed accurately, though it is probably low. The remaining cases of congenital pyloric stenosis-those which appear to form the vast majority-are those in which symptoms, once initiated, are for some time progressive, and which, without treatment, recover only after a prolonged illness or else die. It is to such cases that the term ' manifest' is here being applied.

In an attempt to determine the frequency of congenital pyloric stenosis an endeavour has been made to trace all cases occurring in Newcastle-on-Tyne infants born during the years 1939 to 1942 inclusive. The conditions in Newcastle are peculiarly favourable to an investigation of this type, especially in regard to numbers involved and to the clinic and hospital arrangements. A local knowledge of these conditions justifies the view that almost every case of manifest congenital pyloric stenosis, as defined above, does at some stage reach one of four hospitals or one of a number of nursing homes, and the figures shown below have been obtained by a scrutiny of the records of these four hospitals, and from replies to a questionnaire sent to the nursing homes. It is known from the report of Spence and Miller (1940) that no case of congenital pyloric stenosis died at home in Newcastle during the year 1939. Care has been taken to include only 'Newcastle babies', that is infants born to Newcastle parents; no baby born in Newcastle of parents not resident in Newcastle has been included. In this way the number of cases can be related directly to the number of births for Newcastle in the same period. The validity of the figures rests finally on the diagnostic criteria by which cases have been included in or rejected from the series. In all but two of the cases included the diagnosis was confirmed by operation; in each of the remaining two the history was typical, visible gastric peristalsis was present, a pyloric tumour was palpable, and gastric lavage showed evidence of considerable gastric retention. The criteria of rejection are more difficult to state. Most of the cases (36 out of 49) were admitted to one hospital; at this hospital the writer has examined all the in-patient and out-patient records of the years in question, and found it unnecessary to reject any case in which the clinical picture was suggestive of pyloric stenosis. At a second hospital, which yielded 11 cases, all in-patient records were examined, with a similar result; very few babies were treated as out-patients at this hospital during the years of the survey. It was known to the writer that relatively few cases of pyloric stenosis were treated at the third hospital, and in this no records were examined except those of infants diagnosed as pyloric stenosis; only one Newcastle case was found, and there were no 'doubtful' cases. At the fourth hospital an examination of the admission register revealed no cases of pyloric stenosis, but it was customary over the period surveyed for any infant reaching the hospital with a suspicion of pyloric stenosis to be transferred to the first hospital mentioned. The figure for the nursing homes is based purely on replies to a questionnaire; only one case was reported.

The total numbers of cases from these sources were, for the years 1939, 1940, 1941 and 1942 respectively, 10,16, 7 and 16 . During these same years the numbers of live births to Newcastle parents were $4,599,4,454,4,115$ and 4,289 respectively. Thus, out of 17,457 live born infants to Newcastle parents, 49 are known to have suffered from congenital pyloric stenosis, an incidence of 0.28 per cent. $( \pm 0.08$ per cent. $)$.

There is no statistically significant difference between this figure and the estimate of 0.40 per cent. given by Wallgren (1941) for Götheberg over the years 1934 to 1940 inclusive, his figure being based on 102 cases out of 25,642 live births. (The standard error of the difference between 0.28 per 
cent. of 17,457 and 0.40 per cent. of 25,642 is 0.06 per cent.).

The importance of an estimate of this type is partly scientific and partly practical. Congenital pyloric stenosis is a condition which is, to a large extent, determined genetically (Cockayne and Penrose, 1943), and one would expect racial differences in incidence. As most reports from Latin America are of single cases, it may be presumed that the incidence there is much lower than in the United Kingdom, and Wallgren (1941) quotes Vilen as stating that pyloric stenosis is extremely rare in African native infants. These, however, are but impressions; they can be confirmed or refuted only when figures of incidence from these countries can be compared with those of Wallgren and those presented here.

From the practical standpoint, it can be argued that, as there are at present approximately 600,000 live births in England and Wales each year, any comprehensive medical scheme should offer facilities for the treatment of between 1,200 and 2,160 cases of congenital pyloric stenosis annually. That such facilities are not now available is suggested by a consideration of mortality figures. During the years 1939, 1940, 1941 and 1942 respectively, 335,
360,389 and 359 deaths were registered as being due to congenital pyloric stenosis. Assuming the higher incidence figure, 2,160 cases annually, an average of 360 deaths indicates a case mortality of 16 per cent.; the incidence may well be below this maximum figure, giving an even higher mortality figure.

Summary

Arguments are given for considering the incidence of congenital pyloric stenosis in the United Kingdom to be in the order of three per thousand live births. This figure is not significantly different from that given by Wallgren for Sweden.

The writer is indebted to Dr. Percy Stocks for the mortality figures, and to the Staffs of the Newcastle hospitals and nursing homes for their co-operation.

\section{REFERENCES}

Bexelier, G. (1939). Acta Pediat., 25, 29.

Cockayne, E. A., and Penrose, L. S. (1943). Ohio J. Sci., 43, 1 .

Lewis, F. L. K. (1944). Brit. med. J., 1, 221.

Malmberg, N. (1939). Nord. Med., 4, 3553.

Spence, J. C., and Miller, F. J. W. (1940). ' Report of an Investigation into the Causes of Infantile Mortality in Newcastle-upon-Tyne during the year 1939.' Newcastle-upon-Tyne.

Wallgren, A. (1937). Svenska lak. tidning., 34, 635. (1941). Amer. J. Dis. Child., 62, 75i 